\title{
Identificación de lesiones testiculares no palpables por medio de ultrasonografía en toros
}

\section{Identification of non-palpable testicular lesions using ultrasound imaging in bulls}

\author{
Rogério Oliveira Pinho ${ }^{\text {*}}$; José Carlos Montes Vergara ${ }^{2}$; Deiler Sampaio Costa ${ }^{3}$; João Gabriel da Silva Neves ${ }^{4}$; \\ Jeanne Broch Siqueira5; Leonardo Franco Martins ${ }^{6}$; José Domingos Guimarães ${ }^{7}$
}

1Ph.D., Minitub do Brasil, Porto Alegre, Río Grande del Sur, Brasil; e-mail: rpinho@minitube.com.br; Dhttps://orcid.org/0000-0003-3734-7916

${ }^{2}$ MVZ, M.Sc. Ph.D., Corporación Colombiana de Investigación Agropecuaria - AGROSAVIA, Centro de Investigación Obonuco. Pasto - Nariño, Colombia; e-mail: jcmontes@agrosavia.co; Dhttps://orcid.org/0000-0001-8455-9060

${ }^{3}$ Ph.D. Veterinario independiente. Campo Grande, Mato Grosso del Sur, Brasil; e-mail: deiler.costa@outlook.com; Dhttps://orcid.org/0000-0001-8151-3008 ${ }^{4}$ M.Sc., TJSP, Atibaia, São Paulo, Brasil; Dhttps://orcid.org/0000-0002-6588-0171

${ }^{5}$ Ph.D., Universidade Federal do Vale do Jequitinhonha e Mucuri - UFVJM/MG. Unai, Minas Gerais, Brasil; e-mail: jeanne.siqueira@ufvjm.edu.br; Dhttps:// orcid.org/0000-0002-1903-7554

${ }^{6}$ Ph.D., Fertilivet, Balneário Camboriú, Santa Catalina, Brasil; e-mail: leonardofmpr@yahoo.com.br; Dhttps://orcid.org/0000-0001-8836-5343

${ }^{7}$ Ph.D., Universidade Federal de Viçosa - UFV/MG. Viçosa, Minas Gerais, Brasil; Dhttps://orcid.org/0000-0002-5512-7194

*autor para correspondencia: jcmontes@agrosavia.co

Cómo citar: Pinho, R.O.; Montes Vergara, J.C.; Costa, D.S.; Neves, J.G.S.; Siqueira, J.B.; Martins, L.F.; Guimarães, J.D. 2019. Identificación de lesiones testiculares no palpables por medio de ultrasonografía en toros. Rev. U.D.C.A Act. \& Div. Cient. 22(2):e1157. http://doi. org/10.31910/rudca.v22.n2.2019.1157

Artículo de acceso abierto publicado por Revista U.D.C.A Actualidad \& Divulgación Científica, bajo una licencia Creative Commons CC BY-NC 4.0

Recibido: Febrero 1 de 2019

Aceptado: Octubre 30 de 2019

Editado por: Ingeborg Zenner de Polanía

\section{INTRODUCCIÓN}

Con el objeto de propiciar un diagnóstico rápido, preciso y seguro, la ultrasonografía se constituye en un método valioso en la reproducción animal, ya que permite evaluar los órganos reproductivos internos con precisión anatómica y de forma no invasiva, segura y puede ser usada rutinariamente (Ribadu \& Nakao, 1999; Kastelic \& Brito, 2012; Sousa et al. 2015; Tomlinson et al. 2017). De esta manera, el uso de la ultrasonografía asociada al examen andrológico se muestra importante, especialmente, en la identificación y la caracterización de patologías subclínicas (Kastelic \& Brito, 2012; Kastelic, 2014).
A pesar de las ventajas de la ultrasonografía, su utilización en el diagnóstico andrológico ha sido limitado, debido a la escasez de estudios de correlación entre la intensidad de pixeles y patologías espermáticas (Pinho et al. 2013); sumado a lo anterior, el análisis de la imagen es subjetivo. Siendo así, atribuir valores a los diferentes tonos de la escala de grises posibilita la determinación cuantitativa del patrón de normalidad para el parénquima testicular (Cardilli et al. 2012).

Considerando lo expuesto, el establecimiento de parámetros ultrasonográficos para las dimensiones testiculares y caracterización 
de imágenes normales, se hace necesario para avanzar en estudios más detallados asociados a condiciones degenerativas y patológicas de los testículos (Ribadu \& Nakao, 1999). Según Chapwanya et al. (2008), la evaluación de la ecogenicidad testicular permite también la identificación de lesiones palpables y no palpables, auxiliando la evaluación de los testículos y permitiendo un diagnóstico de lesiones locales y difusas.

Por lo tanto, el análisis de la intensidad de resolución de la imagen ultrasonográfica puede ser una práctica complementaria en la interpretación de lesiones testiculares durante la evaluación andrológica (Pinho et al. 2013). De esta forma, el presente trabajo tuvo como objetivo estudiar la utilización de la ultrasonografía como prueba complementaria en el diagnóstico de lesiones testiculares, en toros de la raza Nelore.

\section{MATERIALES Y MÉTODOS}

Fueron utilizados 405 toros jóvenes de la raza Nelore, con edad entre los 21 y 33 meses, pertenecientes a un rebaño criado en el Estado de São Paulo, latitud $20-21^{\circ}$ Sur y longitud de $50-51^{\circ}$ Oeste, con temperatura media anual de $24^{\circ} \mathrm{C}$ y precipitación pluviométrica anual de $1.189 \mathrm{~mm}^{3}$.

Los animales fueron criados en un sistema extensivo, con praderas predominantemente de pasto Brachiaria decumbens. Posterior a los 18 meses de edad fueron confinados y alimentados con ensilaje de maíz, sal mineral y agua a voluntad, hasta el momento de la evaluación andrológica.

El examen andrológico fue realizado de acuerdo con los criterios establecidos por el Colegio Brasilero de Reproducción Animal (CBRA, 2013), que señala que el potencial reproductivo es previsto por medio de valores registrados para las características físicas y morfológicas del semen, siendo: $70 \%$ de motilidad espermática progresiva y la suma de anormalidades mayores y menores no deben superar el 30\%; siendo un máximo de 10\% para anormalidades mayores y $20 \%$ para las menores.

Adicionalmente, conforme a las características físicas y morfológicas del semen y afecciones de los testículos, los animales fueron clasificados en dos clases andrológicas: siendo: 1) animales aptos para reproducción y 2) animales no aptos para reproducción, según la clasificación dada por el CBRA (2013). Un animal se consideró no apto para reproducción cuando se presentaron condiciones indeseables o irreversibles al momento de la evaluación andrológica (CBRA, 2013; Menegassi \& Barcellos, 2015).

Se realizó una evaluación ultrasonográfica de todos los animales, empleando un ecógrafo de marca Mindray, modelo DP - 2200 VET, acoplado a un transductor lineal con frecuencia $7,5 \mathrm{MHz}$ y obtenidas imágenes del parénquima testicular, usando gel acústico sobre el escroto y formando imágenes en planos longitudinales, en la cara caudal de los testículos izquierdo y derecho. Se tuvo cuidado para que las regiones fueran medidas englobando solo el parénquima testicular.
Todas las imágenes fueron transferidas al computador; con ayuda del software "Image J" (National Institutes of Health, USA), se realizó el análisis de las imágenes, captando la media de la intensidad de pixeles (IP) de cada imagen de las regiones testiculares, en una escala de valores en pixeles variando de 0 (anecoico, imagen oscura) a 255 (hiperecoico, imagen blanca).

Los análisis de los testículos fueron hechos tomando una región pre-determinada en cada imagen del testículo derecho e izquierdo. Para evaluar la homogeneidad de la ecotextura testicular y el área representativa de pixeles, cada región de las imágenes seleccionadas fue delimitada con cuadrados de $200 \mathrm{~mm}^{2}$ de área (Pinho et al. 2013). Las medias de las características espermáticas fueron obtenidas mediante el programa SAEG versión 9.1 y se realizó la correlación simple de Pearson, entre las características espermáticas y la IP de las imágenes.

\section{RESULTADOS Y DISCUSIÓN}

Las medias obtenidas para las características espermáticas fueron $67,7 \% \pm 15,0$ de motilidad espermática, $26,3 \% \pm 18,0$ de anormalidades totales, $20,8 \% \pm 16,4$ de anormalidades mayores y $5,5 \% \pm 4,5$ de anormalidades menores. Al análisis de correlación entre características espermáticas e IP no se observó asociación. De los 405 toros evaluados, 68,7\% fueron considerados aptos para reproducción y $31,3 \%$ no aptos.

Siete animales $(1,7 \%)$ del total evaluado, mostraron algún tipo de patología testicular no palpable, observando puntos de fibrosis unilateral, fibrosis testicular bilateral grave y mediastino, con presencia de vesículas anecoicas (Figuras 1 y 2). Es de destacar que, dentro de estos siete animales, solo dos toros fueron considerados aptos para reproducción, uno con pequeños puntos de fibrosis y, otro, con mediastino, presentando vesículas anecoicas.

Chapwanya et al. (2008), también identificaron siete toros con lesiones palpables y no palpables, indicando que la ultrasonografía testicular es más sensible y confiable como modalidad de diagnóstico en comparación con la sola palpación. Normalmente, los testículos de animales adultos presentan ecogenicidad moderada, lo cual, permite contrastar con lesiones visibles para la ultrasonografía (Barth et al. 2008; Cardilli et al. 2012).

Ahora, cuando al examen andrológico se asocian las imágenes ultrasonográficas, estas últimas se muestran como una importante prueba complementaria, especialmente, si se trata de desórdenes subclínicos (Gabor et al. 1998), siendo posible evaluar la anatomía de las glándulas sexuales y el parénquima testicular de los reproductores, además de diagnosticar alteraciones andrológicas aún asintomáticas a los exámenes convencionales (Jucá et al. 2009).

El principal uso clínico de la ultrasonografía en la evaluación reproductiva de los toros está en la detección de lesiones graves en los testículos y el escroto (Kastelic, 2014). Según Barth et al. (2008), las lesiones fibrosas del parénquima testicular son comunes, siendo necesaria la determinación de la prevalencia de estas lesiones por 

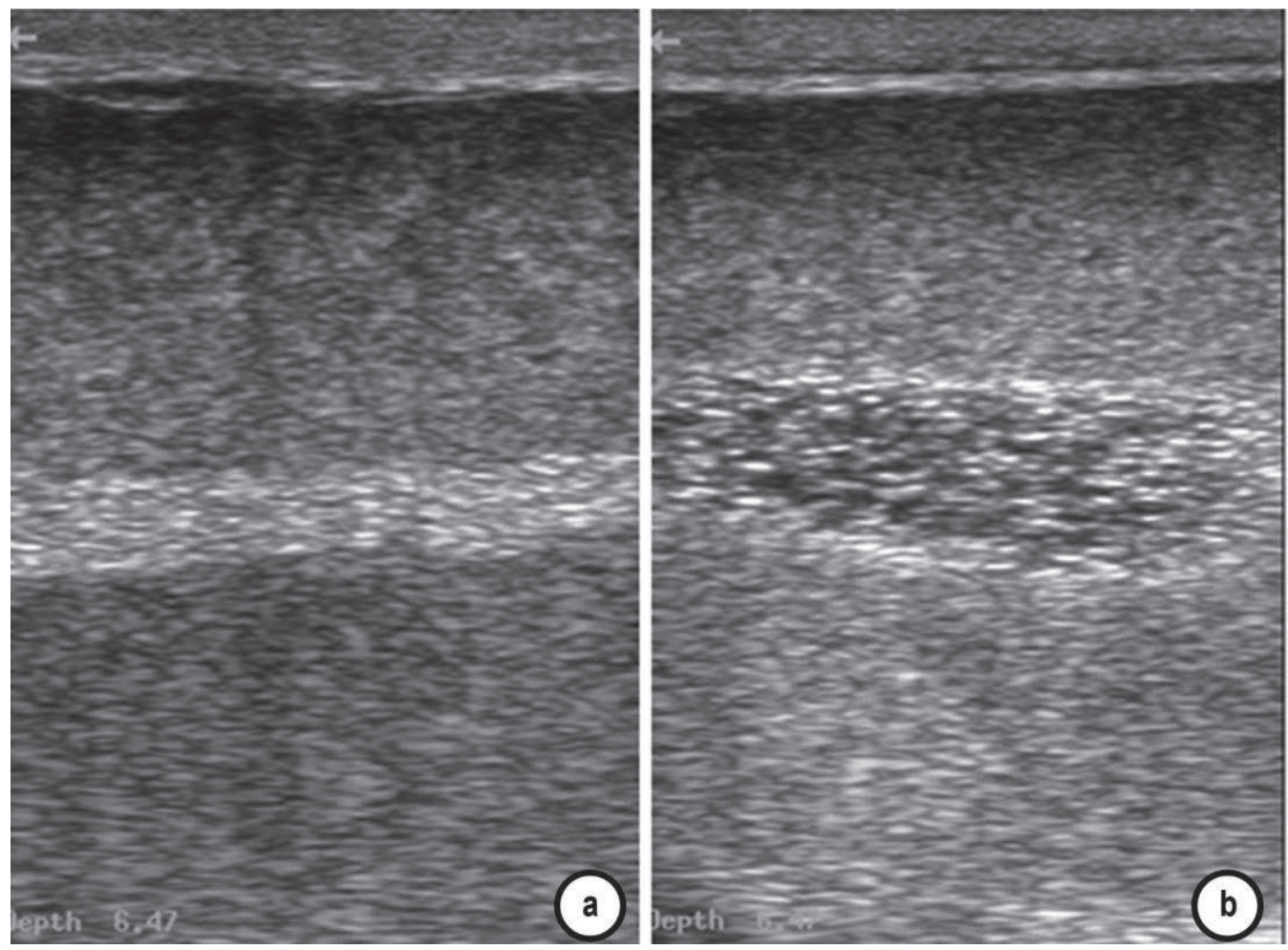

Figura 1. Mediastino. a. normal; b. alterado.

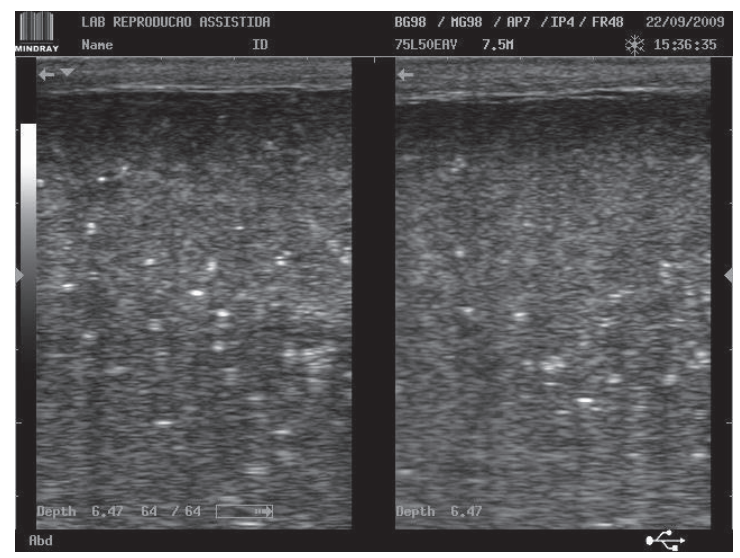

Figura 2. Puntos de fibrosis.

medio de ultrasonografía testicular en toros de diferentes edades, con el fin de relacionar las informaciones de la imagen con la calidad seminal.

Barth et al. (2008) señalan que las alteraciones más evidentes del parénquima testicular, fácilmente detectadas con el ecógrafo, pueden presentar correlación con la calidad seminal. Arteaga et al. (2005) encontraron que las alteraciones en la ecogenicidad del parénquima testicular se asociaron al aumento en las anormalidades espermáticas.
Recientemente, el estudio de Tomlinson et al. (2017) no evidenció correlación entre la calidad del semen de los andrológicos con la intensidad de pixeles en el testículo, sugiriendo que la intensidad de pixeles no sería útil para la predicción de la calidad del semen, pero sí para la identificación de animales con lesiones fibróticas graves, en las cuales, se puede reducir la producción diaria de espermatozoides.

En la medicina humana, la ultrasonografía distingue diferentes patologías como: colección de líquido intratesticular, orquitis, 
lesiones císticas, hematomas, hernia, degeneración, torsión, isquemia, epididimitis y masas extratesticulares, incluyendo neoplasias (Pechman \& Eilts, 1987). Hamm \& Fobbe (1995) informaron que existe, aun, una gran importancia clínica en el estudio de las diferencias de ecogenicidad del parénquima testicular entre niños y adultos, pues desórdenes testiculares, como tumores y procesos inflamatorios, son típicamente representados por lesiones ultrasonográficas hipoecoicas, que no son visibles en contraste con la ecogenicidad moderada de los testículos "maduros".

En este sentido, la evaluación de la ecogenicidad testicular permite la identificación de lesiones palpables y no palpables, ayudando en la evaluación de los testículos y permitiendo un diagnóstico de lesiones focales o difusas (Chapwanya et al. 2008). En el caso de degeneración testicular, por ejemplo, ocurre pérdida en la arquitectura del tejido y el parénquima testicular se vuelve hiperecoico con el pasar del tiempo, caracterizado por la formación de sombras (Gnemmi \& Lefebvre, 2009).

Así como en el presente estudio (Figura 2), donde se observaron diversas alteraciones durante la evaluación ultrasonográfica de los órganos reproductivos, Gnemmi \& Lefebvre (2009) también identificaron lesiones palpables y no palpables. Sousa et al. (2015) evaluaron toros de raza Nelore entre 5 y 10 años y hallaron a la evaluación ultrasonográfica animales con degeneración testicular, orquitis, hidrocele, calcificación y quistes en la región del parénquima testicular, recomendando su uso como herramienta de diagnóstico complementaria.

Chapwanya et al. (2008), al evaluar 32 taurinos con media de 5,6 años de edad, identificaron siete toros con lesiones testiculares detectables al examen ultrasonográfico, dos de ellos, con grados de fibrosis testicular a punto de comprometer la calidad seminal, indicando que la ultrasonografía testicular es más sensible y confiable como modalidad de diagnóstico de lo que la sola palpación.

Asimismo, Barth et al. (2008) observaron que los mismos toros con grados de fibrosis muy graves produjeron semen con hasta $94 \%$ de espermatozoides morfológicamente normales. Estos resultados indican que la presencia de cantidades relativamente grandes de tejido cicatrizal en el interior del parénquima testicular no impidió la producción de espermatozoides normales por las demás áreas del parénquima testicular. En el caso del presente estudio, si bien se observó un animal con pequeños puntos de fibrosis, se consideró apto para la reproducción.

Según Barth et al. (2008) serían necesarias grandes cantidades de tejido cicatrizal para reducir la producción espermática. Si bien, Tomlinson et al. (2017) no observaron correlación entre la calidad seminal y las mediciones de PI, sí mostraron que la puntuación visual macroscópica de las imágenes testiculares se compara con el análisis computarizado de PI en la identificación de animales con fibrosis testicular.

Por los diversos resultados observados en la evaluación andrológica de los reproductores, establecer diagnóstico y pronóstico seguros para cualquier alteración observada, depende de la realización detallada de la anamnesis, examen clínico general y andrológico, con evaluación de los aspectos físicos y morfológicos del semen en exámenes consecutivos, además de la evaluación ultrasonográfica, buscando evitar el descarte de animales con base en apenas una evaluación, pues estos, una vez recuperados, readquieren la fertilidad normal (Van Camp, 1997) y, por lo que puede ser observado, dependiendo del grado de alteraciones, pueden no llegar a alterar la calidad espermática, no comprometiendo la vida reproductiva de los reproductores de una granja.

En el presente estudio, la utilización de las imágenes ultrasonográficas mostró ser una herramienta complementaria y eficaz en la identificación e interpretación de lesiones testiculares no palpables durante la evaluación andrológica, fortaleciendo la evaluación y la selección de reproductores.

Conflictos de intereses: El manuscrito fue preparado y revisado con la participación de todos los autores, quienes declaramos que no existe ningún conflicto de intereses que ponga en riesgo la validez de los resultados presentados.

\section{REFERENCIAS}

1. ARTEAGA, A.A.; BARTH, A.D.; BRITO, L.F. 2005. Relationship between semen quality and pixel-intensity of testicular ultrasonograms after scrotal insulation in beef bulls. Theriogenology. 64(2):408-415. https://doi. org/10.1016/j.theriogenology.2004.12.008

2. BARTH, A.D.; ALISIO, L.; AVILÉS, M.; ARTEAGA, A.A.; CAMPBELL, J.R.; HENDRICK, S.H. 2008. Fibrotic lesions in the testis of bulls and relationship to semen quality. Anim. Reprod. Sci. 106(3-4):274-288. https://doi. org/10.1016/j.anireprosci.2007.05.002

3. CARDilli, D.J.; TONIOLLO, G.H.; PASTORE, A.A.; CANOLA, J.C.; OLIVEIRA, J.A.; MERCADANTE, M.E.Z. 2012. Ultrassonografia testicular em bovinos jovens da raça Nelore criados em sistema extensivo. Arq. Bras. Med. Vet. Zootec. 64(1):75-82. http://dx.doi.org/10.1590/ S0102-09352012000100012

4. CHAPWANYA, A.; CALLANAN, J:; LARKIN, H.; KEENAN, L.; VAUGHAN, L. 2008. Breeding soundness evaluation of bulls by semen analysis, testicular fine needle aspiration cytology and trans-scrotal ultrasonography. Ir. Vet. J. 61(5):315-318. https://doi.org/10.1186/2046-0481-61-5315

5. COLÉGIO BRASILEIRO DE REPRODUÇÃO ANIMAL, CBRA. 2013. Manual para exame andrológico e avaliação de sêmen animal 3.ed. Belo Horizonte. 104p.

6. GABOR, G.; SASSER, R.G.; KASTELIC, J.P.; MÉZES, M.; FALKAY, Gy.; BOZÓ, J.; VÖLGYI CSÍK, J.; BARÁNY, 
I.; HIDAS, A.; SZÁSZ, Jr.; BOROS, G. 1998. Computer analysis of video and ultrasonographic images for evaluation of bull testes. Theriogenology. 50(2):223-228. https://doi.org/10.1016/S0093-691X(98)00129-0

7. GNEMMI, G.; LEFEBVRE, R.C. 2009. Ultrasound imaging of the bull reproductive tract: an important field of expertise for veterinarians. Vet. Clin. North Am. Food Anim. Pract. 25(3):767-779. https://doi.org/10.1016/j.cvfa.2009.07.006

8. HAMM, B.; FOBBE, F. 1995. Maturation of the Testis: ultrasound evaluation. Ultrasound Med. Biol. 21(2):143147. https://doi.org/10.1016/S0301-5629(94)00088-3

9. JUCÁ, A.F.; MOURA, J.C.; GUSMÃO, A.L.; BITTENCOURT, T.C.; NASCIMENTO, M.C.; BARBOSA, C.M. 2009. Avaliação ultrassonográfica dos testículos e das glândulas sexuais anexas de carneiros Santa Inês. Ciência Anim. Bras. 10(2):650-659.

10. KASTELIC, J.P.; BRITO, L.F.C. 2012. Ultrasonography for Monitoring Reproductive Function in the Bull. Reprod Domest Anim. 47(Suppl.3):45-51. https://doi. org/10.1111/j.1439-0531.2012.02042.x

11. KASTELIC, J.P. 2014. Theriogenology Understanding and evaluating bovine testes. Theriogenology. 81(1):18-23. https://doi.org/10.1016/j.theriogenology.2013.09.001

12. MENEGASSI, S.R.O.; BARCELLOS, J.O.J. (Coords.). 2015. Aspectos Reprodutivos do Touro: Teoria e Prática. Guaíba: Agrolivros. 280p.
13. PECHMAN, R.D.; EILTS, B.E. 1987. B-mode ultrasonography of the bull testicle. Theriogenology. 27(2):431-441. https:// doi.org/10.1016/0093-691X(87)90231-7

14. PINHO, R.O.; COSTA, D.S.; SIQUEIRA, J.B.; MARTINS, L.F.; CHAYA, A.Y.; NETO, T.M.; GUIMARÃES, S.E.; GUIMARÃES, J.D. 2013. Correlation of sexual maturity stage with testicular echotexture in Young Nellore bulls. Acta Sci. Vet. 41:1161.

15. RIBADU, A.Y.; NAKAO, T. 1999. Bovine reproductive ultrasonography: A review. J. Reprod. Dev. 45(1):13-28. https://doi.org/10.1262/jrd.45.13

16. SOUSA, K.C.; ROLIM FILHO, S.T.; RIBEIRO, H.F.L.; VALE, W.G. 2015. Ultrasound as tool for diagnosis of diseases of the reproductive tract bulls. Arch. Vet. Sci. 20 (3): 89-99. https://doi.org/10.5380/avs.v20i3.41242

17. TOMLINSON, M.;JENNINGS, A.; MACRAE, A.; TRUYERS, I. 2017. The value of trans-scrotal ultrasonography at bull breeding soundness evaluation (BBSE): The relationship between testicular parenchymal pixel intensity and semen quality. Theriogenology. 89:169-177. https://doi. org/10.1016/j.theriogenology.2016.10.020

18. VAN CAMP, S.D. 1997. Common causes of Infertility in the bull. Vet. Clin. North Am. Small Anim. Pract. 13(2):203232. https://doi.org/10.1016/S0749-0720(15)30336-4 